Insight, part of a Special Feature on $\underline{\text { Scale and Governance }}$

\title{
Panarchy Rules: Rethinking Resilience of Agroecosystems, Evidence from Dutch Dairy-Farming
}

\author{
$\underline{\text { Dirk F. van Apeldoorn }}^{1,2}, \underline{\text { Kasper Kok }}^{1}$, Marthijn P.W. Sonneveld ${ }^{1}$, and Tom (A.) Veldkamp ${ }^{1,2,3}$
}

\begin{abstract}
Resilience has been growing in importance as a perspective for governing social-ecological systems. The aim of this paper is first to analyze a well-studied human dominated agroecosystem using five existing key heuristics of the resilience perspective and second to discuss the consequences of using this resilience perspective for the future management of similar human dominated agroecosystems. The human dominated agroecosystem is located in the Dutch Northern Frisian Woodlands where cooperatives of dairy farmers have been attempting to organize a transition toward more viable and environmental friendly agrosystems. A mobilizing element in the cooperatives was the ability of some dairy farmers to obtain high herbage and milk yield production with limited nitrogen fertilizer input. A set of reinforcing measures was hypothesized to rebalance nitrogen flows and to set a new equilibrium. A dynamic farm model was used to evaluate the long-term effects of reinforcing measures on soil organic matter content, which was considered the key indicator of an alternative system state. Simulations show that no alternative stable state for soil organic matter exists within a plausible range of fertilizer applications. The observed differences in soil organic matter content and nutrient use efficiency probably represent a time lag of longterm nonequilibrium system development. The resilience perspective proved to be especially insightful in addressing interacting long-term developments expressed in the panarchy. Panarchy created a heterogeneity of resources in the landscape providing local landscape-embedded opportunities for high N-efficiencies. Stopping the practice of grassland renewal will allow this ecological landscape embedded system to mature. In contrast, modern conventional dairy farms shortcut the adaptive cycle by frequent grassland renewals, resulting in high resilience and adaptability. This comes at the cost of long-term accumulated ecological capital of soil organic matter and transformability, thus reinforcing the incremental adaptation trap. Analysis of such a human dominated agroecosystem reveals that rather than alternative states, an alternative set of relationships within a multiscale setting applies, indicating the importance for embedding panarchy in the analysis of sustainable development goals in agroecosystems.
\end{abstract}

Key Words: agroecosystems; dairy farming; panarchy; Northern Frisian Woodlands, The Netherlands; resilience; soil organic matter

\section{INTRODUCTION}

Classic agronomical research has been largely driven by a commodity-based, plot- or field-scale approach with an emphasis on the potential for short-term maximization of crop and livestock production (Giller et al. 2006). Recent studies demonstrate that multiple spatial and temporal scales need to be addressed to understand current patterns in agricultural system functioning (Sonneveld et al. 2002, Giller et al. 2006, Schulp and Veldkamp 2008). In addition, the role of rural areas is changing and ecosystem services other than primary production are increasingly valued as well (Carpenter et al. 2009). This changing role of rural areas has led to explorations of new modes of rural governance (Renting and van der Ploeg 2001, Wiskerke et al. 2003). At the same time, agriculture faces the challenge of an increasing global demand for food while maintaining the capacity of the biosphere to provide goods and services in the long term (Foley et al. 2005, Kiers et al. 2008).

To face this challenge, new sustainable development perspectives are needed (Veldkamp et al. 2009). The resilience perspective has become 
increasingly popular because it appeals to the notion of sustainable and dynamic development (Carpenter et al. 2001, Kremen and Ostfeld 2005). Resilience has been growing in importance as a perspective for understanding, managing, and governing complex linked systems of people and nature (Anderies et al. $2006 a$, Folke 2006). From a measure of how fast a system returns to an equilibrium state after a disturbance, resilience has evolved to a perspective that is used by various scientific disciplines to analyze ecological as well as social-ecological systems (Anderies et al. 2006b, Brand and Jax 2007). The resilience perspective specifically focuses on the interplay between periods of gradual change and periods of rapid change, and how such dynamics interact across temporal and spatial scales (Folke 2006).

Agroecosystems in which humans manage and use communities of plants, animals, their biophysical environment, and their interactions (Gomiero et al. 2006) can be considered as social-ecological systems. In most modern agroecosystems, the native ecosystem has been replaced and has been dominated by humans over long periods of time. Although they are human dominated, agroecosystems still rely on ecological processes.

The resilience perspective has originally been applied to social-ecological systems where the native ecosystem is still in place. The aim of this study is to apply the resilience perspective to a human dominated agroecosystem. The aim is realized by addressing two objectives: (1) analyze a well-studied agroecosystem using five key heuristics of the resilience perspective, and (2) discuss the consequences of using this resilience perspective for the future management of similar human dominated agroecosystems.

\section{MATERIAL AND METHODS}

To organize our analysis on resilience of agroecosystems, we use a set of five heuristics provided by Walker et al. (2006), and that are generally accepted as important elements of resilience. The heuristics are: the adaptive cycle, panarchy, resilience, adaptability, and transformability. Below we introduce the heuristics and their application to agroecosystems.

\section{Agroecosystems and the resilience heuristics}

\section{Adaptive cycle}

The adaptive cycle describes four commonly occurring phases of growth, conservation, collapse, and reorganization in social-ecological systems. For agroecosystems, dynamics of the adaptive cycle might not always hold. Allison and Hobbs (2004) for example, found a pathological state of lock-in. Exceptions to the adaptive cycle seem particularly to occur under the influence of large, external disturbances and a lack of critical forms of capital (Walker et al. 2006).

\section{Panarchy}

A panarchy is a heuristic of linked, hierarchically arranged adaptive cycles. The linkages between the adaptive cycles in the panarchy might cause cascading events: the collapse of one level inducing the exceeding of other thresholds. Kinzig et al. (2006) describes several examples of agroecosystems where changes at field level might cause regional change. Such cascading events often lead to very resilient, although often less desirable, alternative states. Moreover, there is strong evidence that agricultural modification can produce a variety of ecological regime shifts that operate across a range of spatial and temporal scales and domains (Gordon et al. 2008).

\section{Resilience}

Because of increased popularity of the resilience concept (Brand and Jax 2007), resilience is often confused with sustainability or is considered inherently good. We use resilience as a nonnormative heuristic. Resilience describes if and how a disturbed system returns to its former functioning. The high resilience of the pathological state of lockin (Allison and Hobbs 2004) and the cascading events of Kinzig et al. (2006) are examples of high resilience where degradation within the agroecosystem creates a persistent system, which is difficult to disturb.

\section{Adaptability}

Adaptability is the capacity of humans to manage resilience. Modern agroecosystems have a mixed reputation on adaptability. On the one hand, they are able to stabilize production via access to external resources, e.g., artificial fertilizers, concentrates 
etc., thus showing a high adaptability to external fluctuations. The access to external resources comes at a cost of dependency on forces that farmers are unable to control, and that must be taken as constraints upon the system. At the regional level, however, the strategy followed continues to have impact on the slow ecological variables, reducing the potential or capital through time (Anderies et al. $2006 a$ ). Thus, an undesirable system configuration is created, leading to a reduced adaptive capacity (Milestad and Darnhofer 2003).

\section{Transformability}

Transformability is the capacity of the actors within the system to create a fundamentally new system when the existing configuration is untenable. Determinants of transformability include incentives to change, cross-scale awareness, experimentation, reserves, and convertible assets (Walker et al.2006). Highly resilient, undesirable regimes tend be created by cascading events in the panarchy (Kinzig et al. 2006). Modern agroecosystems can generally be seen as low transformable, with eroded natural resources, a low diversity in crops, large scale subsidies, vested interests of the conglomerated agri-foodchain reducing innovation, diversity, and human organization.

\section{Description of study area}

The Northern Frisian Woodlands is an area of about 60,000 ha located in the north of the Netherlands and is dominated by dairy farming. In the 1990s, the exceedance of environmental quality standards for atmosphere and groundwater resulted in national regulations that forced farmers into new modes of organization. Because some of the imposed regulations conflicted with local conditions, regional environmental farmer cooperatives were established with the aim to move toward viable and environmentally friendly agrosystems that fit in their landscape (Renting and van der Ploeg 2001). With the rural-environmental cooperatives, new modes of science, learning, governance, and rural development were explored by communities of practice, in which scientists work together with various stakeholders and policy makers of different scales in a joint learning mode (Renting and van der Ploeg 2001, Roep et al. 2003, Stuiver et al. 2003, van der Ploeg 2003, Wiskerke et al. 2003, Eshuis and Stuiver 2005, Bouma et al. 2008).
A mobilizing element in the cooperatives was the ability of some farmers to obtain high herbage and milk yield production with limited nitrogen fertilizer input (Reijs et al. 2004). A regional nutrient management project was initiated to perform on-farm analysis of nitrogen balances, and to assist farmers in the transition to more sustainable farming with reduced nutrient inputs (Groot et al. 2006). Reijs et al. (2004) reported that farmers in the Northern Frisian Woodlands had found a new equilibrium by rebalancing nitrogen flows resulting in a well-balanced system (Groot et al. 2006). This suggests that from a resilience perspective, possibly an alternative stable state was discovered. The alternative state might not be a true alternative stable state (Scheffer et al. 2001), but at least represents a regime shift in the sense of a drastic change in the properties of a system, resulting from smaller perturbations or smooth changes in independent controlling variables (cf. Scheffer and Carpenter 2003, Walker and Meyers 2004, Kinzig et al. 2006).

\section{Modeling resilience of agroecosystems}

For identifying alternative stable states, system models are particularly useful. They organize the key elements of a case into a structure that can be used to identify the slowly changing variables, stabilizing and destabilizing forces, and important thresholds that determine the resilience of a system (Bennett et al. 2005). In the Northern Frisian Woodlands, farmers and scientists had together identified a set of measures that would mutually reinforce each other and would self-balance the farm (Reijs et al. 2004). Specifically, they experimented with the following measures: reduction of artificial fertilizers and concentrates; a lower crude protein and higher fiber content in the silage; a higher fraction of organic matter and organic nitrogen in the manure; and a limited grassland renewal and maize production.

The measures were considered to reinforce each other. A reduction of artificial fertilizers would lead to lower crude protein content in feed, complemented by cutting the grass later in the season. This diet would in turn increase the $C: N$ ratio, and decrease the inorganic $\mathrm{N}$ content of the manure, in turn leading to higher soil organic matter content, finally leading to reduced need of fertilizers. Although some farmers experimenting with the reinforcing measures also changed other 
Fig. 1. The $\mathrm{N}$ cycle at a dairy farm, the numbers are $\mathrm{N}$ flows $(\mathrm{kg} / \mathrm{ha})$. The upper numbers are averages of farmers applying the reinforcing measures, the lower numbers are averages of conventional farmers in the area. Data are based on group averages in 1997 (Groot et al. 2006) and 17.8\% and 16.1\% efficiency of the cow.

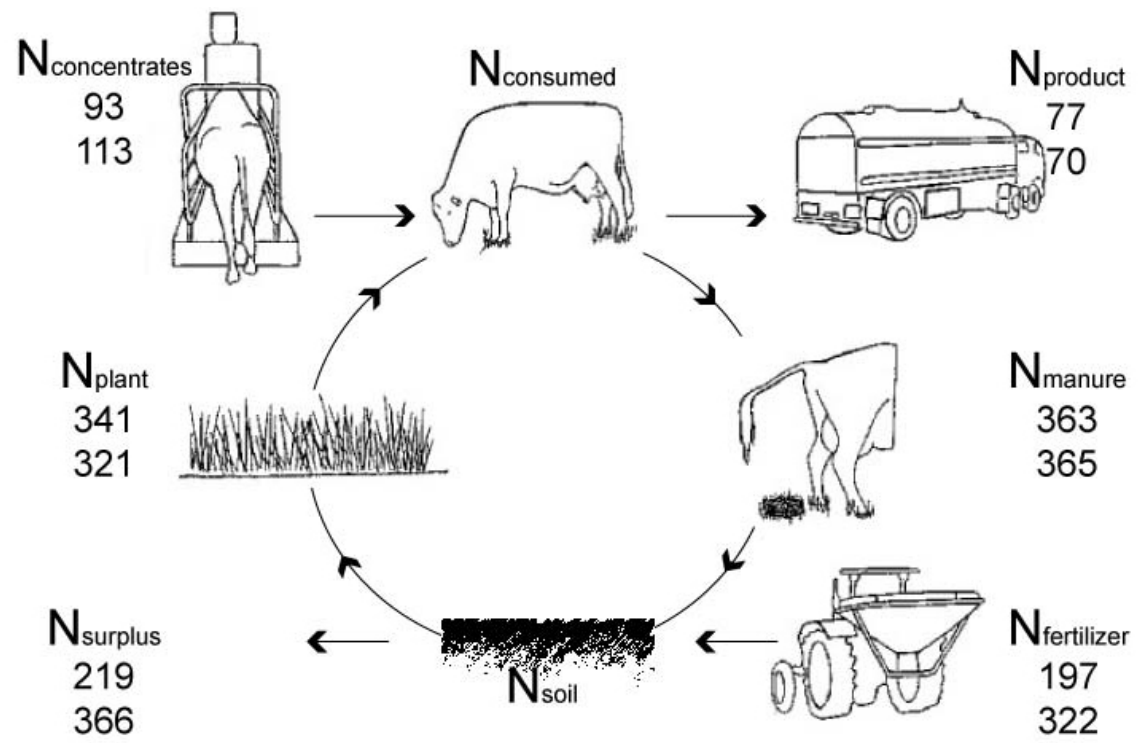

aspects of their farming practice, for example applying microbiological active additives to the manure, and manure application practices, the main aim of the reinforcing measures was to reduce external fertilizer need (Reijs et al. 2004). Grassland renewal and maize production require plowing of the field, resulting in lower soil organic matter contents (Hanegraaf et al. 2009). When plowed and converted to arable land, $50 \%$ of the organic matter is lost within six years (Whitmore et al. 1992). Therefore, soil organic matter content can be conserved by limiting these practices.

\section{Key variables}

Nitrogen and soil organic matter were used as key variables for modeling the resilience of intensive dairy farming. Nitrogen is considered a key variable for intensive dairy farming (Whitehead 1995). Moreover, inputs and outputs are commonly monitored in Dutch dairy systems for which generally applicable process-based models exist (Van den Pol-van Dasselaar and Lantinga 1995, Kohn et al. 1997, Groot et al. 2003, Schröder et al.
2003). Soil organic matter is a slow variable and because of its impact on other physical, chemical, and biological soil properties, it is often chosen as the most important indicator for soil quality and agronomic sustainability (Reeves 1997). Additionally, the observed differences in $\mathrm{N}$ balances were considered to be mainly caused by differences in water balance and soil organic matter (Groot et al. 2007).

\section{Model description of an intensive dairy farm in the Netherlands}

In the studied intensive dairy farming practice, only part of the total dry matter production is sold or consumed by cattle (Whitehead 1995). A large part remains on the farm as roots, stubble, manure, etc., and the remains are part of a nutrient cycle on the farm. In Figure 1, the flows of the nitrogen cycle and their magnitude on conventional farms (lower number) and farms that are experimenting with the reinforcing measures (upper number) are given. 
Next to export and import of manures, crops, animals, and animal products, the $\mathrm{N}$-cycle receives inputs from atmospheric deposition, biological fixation, fertilizers, and concentrates, and loses nitrogen to the atmosphere, the groundwater, or surface waters. Whereas most resilience models use hypothetical nonlinear functions to describe multiple stable states and system behavior, we based our model on observed relationships that have been published in Whitehead (1995), Groot et al. (2003), and Reijs et al. (2007). We were interested in the interaction of management and ecological processes as observed in the Northern Frisian Woodlands. We generalized relationships and did not model a particular farm or make prescriptions on management practice. The general relationships could be verified by the data available from the nutrient management project at the Northern Frisian Woodlands.

\section{Feedbacks of nitrogen and soil organic matter of} intensive dairy farming

The cycling of nitrogen is divided between organic and inorganic nitrogen. The carbon to nitrogen $(\mathrm{C}$ : $\mathrm{N})$ ratio regulates the conversion from the organic nitrogen form to the inorganic nitrogen form (Janssen 1996). In return, the nitrogen and carbon fixed in organic matter is mainly a function of available inorganic nitrogen taken up by the grass. The division between the nitrogen bound to organic matter and inorganic nitrogen determines the speed of recycling. Inorganic nitrogen is a fast component of the cycle and is very volatile, and can be taken up by plants. We indicated the internal feedbacks of nitrogen and interactions with soil organic matter of intensive dairy farming in the nitrogen cycle at farm level (Fig. 2).

Grass has a high capacity of soil mineral nitrogen $\left(\mathrm{N}_{\min }\right)$ uptake, but risks for environmental losses increase with higher amounts of mineral nitrogen in the soil (Sonneveld et al. 2002). Part of the nitrogen captured in the plant $\left(\mathrm{N}_{\text {plant }}\right)$ is harvested or grazed and consumed by livestock $\left(\mathrm{N}_{\text {consumable }}\right)$. Increasing mineral nitrogen in the soil has two effects: (1) the root/shoot ratio of the biomass becomes lower (Van den Pol-van Dasselaar and Lantinga 1995), and (2) the nitrogen concentration in the plant increases (Whitehead 1995). The higher the uptake of nitrogen by the biomass, the larger the proportion of nitrogen that is harvested and removed from the field (depicted as ++ in Figure 2). Nitrogen consumed by cattle is distributed between urine,

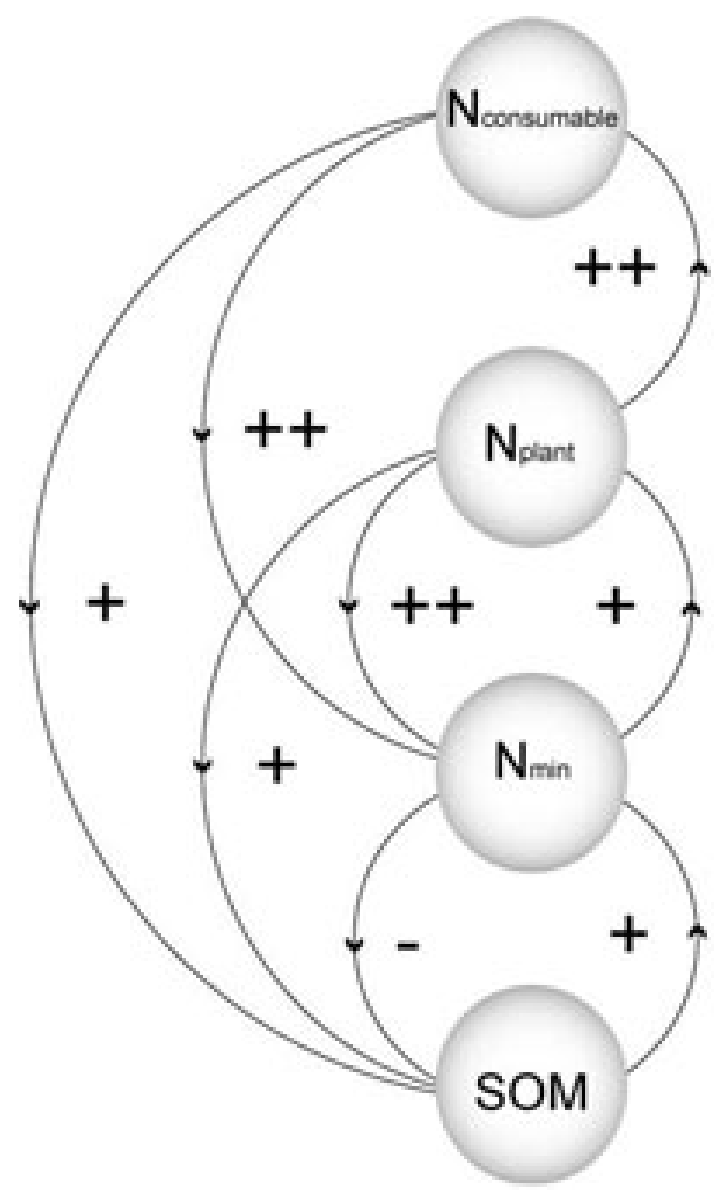

\begin{abstract}
Fig. 2 Feedbacks within the nitrogen cycle at farm level. Nonlinear increases in flows are depicted as ++. For description of feedbacks see text.
\end{abstract}

feces, milk, and meat. The higher the concentration of nitrogen (crude protein) in the diet of cattle, the higher the proportion of nitrogen that ends up in the urine (Whitehead 1995; depicted as ++ in Figure 2). Part of the nitrogen from feces and urine is lost during housing and storage. The remaining nitrogen in feces and urine is returned to the field as manure. The nitrogen in the urine directly returns as inorganic nitrogen in the soil. The organically bound nitrogen in the feces and soil organic matter (SOM) contributes to the inorganic $\mathrm{N}$ pool via mineralization. The remaining unharvested biomass immobilizes inorganic nitrogen when the $\mathrm{C}: \mathrm{N}$ ratio of the unharvested biomass is higher than that of the decomposing soil microbes (Janssen 1996). With larger amounts of mineral nitrogen available, the $\mathrm{C}$ : $\mathrm{N}$ ratio of the unharvested biomass decreases (Whitehead et al. 1990). When the unharvested 
biomass decomposes, it contributes back to the mineral nitrogen pool. The remaining organic compounds of the feces and the unharvested biomass (mostly roots) contribute to the buildup of the soil organic matter pool. The buildup of soil organic matter is mainly regulated by the input of carbon (Hassink 1994), thus for soil organic matter to increase, more carbon has to be returned to the soil.

The soil inorganic $\mathrm{N}$ pool $\left(\mathrm{N}_{\min }\right)$ and the nitrogen uptake by the plant $\left(\mathrm{N}_{\text {plant }}\right)$ cycle within a year, whereas soil organic matter can have turnover rates of decades or even centuries (Janzen 2005, Schulp and Veldkamp 2008). There are thus two cycles that control the nitrogen in the system. One cycle is from inorganic nitrogen from fertilizer or urine $\left(\mathrm{N}_{\min }\right)$ to the grass $\left(\mathrm{N}_{\text {plant }}\right)$, then to the livestock and back to inorganic nitrogen via urine and mineralization of feces and unharvested biomass. This is a fast cycle, which is used for environmental regulations and nutrient balances. The other cycle is via soil organic matter (SOM) in the soil. This cycle is slower because the turnover rate of soil organic matter is at least one order of magnitude higher.

Details of the model formulation are given in the Appendix 1. To simplify matters, we assumed that the herd size and accompanying milk production follows biomass production. Storage or selling of feed and manure were not included in the model. The model was used to test if alternative stable states could be identified by reducing nitrogen input.

\section{RESULTS AND DISCUSSION}

In this section we first analyze the effect of different fertilizer applications and accompanying farm management using the five heuristics and model simulations. Thereafter, we discuss the consequences of using the resilience perspective on this human dominated agroecosystem.

In Figure 3, the required time is calculated to reach equilibrium conditions for a range of fertilizer applications and soil organic matter contents. The time needed was plotted on the Z-axis, generating a stability landscape (see Scheffer and Carpenter 2003). At the bottom of Figure 3, the solid line shows that over time, for all simulated fertilizer applications, a comparable soil organic matter content is reached.
The simulations show that no true stable alternative state for soil organic matter exists within a range of $50-500 \mathrm{~kg} \mathrm{~N} / \mathrm{ha}$ applications. The relatively flat landscape with the steep gully suggests a low response of soil organic matter to the management variable of artificial fertilizer; the system is resistant to change in fertilizer application. The steep slope at the edge of the gully is not caused by changes in management, but is the effect of a long-term process. Only when the soil organic matter is almost at its equilibrium value does the return time drop. With such a low response of the management variable no catastrophic shifts or thresholds can be detected at this level.

High levels of inorganic nitrogen do not influence the accumulation of soil organic matter. With increasing concentrations of mineral nitrogen, more mineral nitrogen is lost. Thus, given enough time, every reasonable amount of nitrogen fertilizer application would result in the same soil organic matter content. Consequently, differences in soil organic matter cannot be explained by alternative states caused by fertilizer application. Alternatively, the observed differences in soil organic matter content and nutrient use efficiency probably represent systems that are out of equilibrium. This has implications when analyzed using the five heuristics of the resilience perspective.

\section{Discussion of the heuristics}

\section{Adaptive cycle}

Farms that are experimenting with the reinforcing measures aim to optimize nutrient recycling in the system with less dependency on external resources, notably artificial fertilizer. The high productivity of the managed grasslands is reached through a high efficiency of recycling nitrogen in soils that have high organic matter content. This state is comparable with the conservation phase of the adaptive cycle.

Conventional modern farm management is mainly limited by prices of the inputs and constraints of management regulations rather than their recycling of nitrogen. Current policies induce a strategy that aims at optimizing the fast conversion of mineral $\mathrm{N}_{\text {fertilizer }}$ to $\mathrm{N}_{\text {consumable }}$ to get high outputs (Schröder et al. 2003). This can be classified as a command and control strategy (Holling and Meffe 1996) that builds on the fast response of grassland productivity 
Fig. 3. Stability landscape of the interaction between fertilizer input and soil organic matter. For a broad range of soil organic matter values the time of reaching equilibrium conditions with a certain $\mathrm{N}$-fertilizer application is calculated. This period of time needed to reach equilibrium is represented by height of the landscape. Initial condition is a field after maize cultivation and based on Sonneveld et al. (2002).

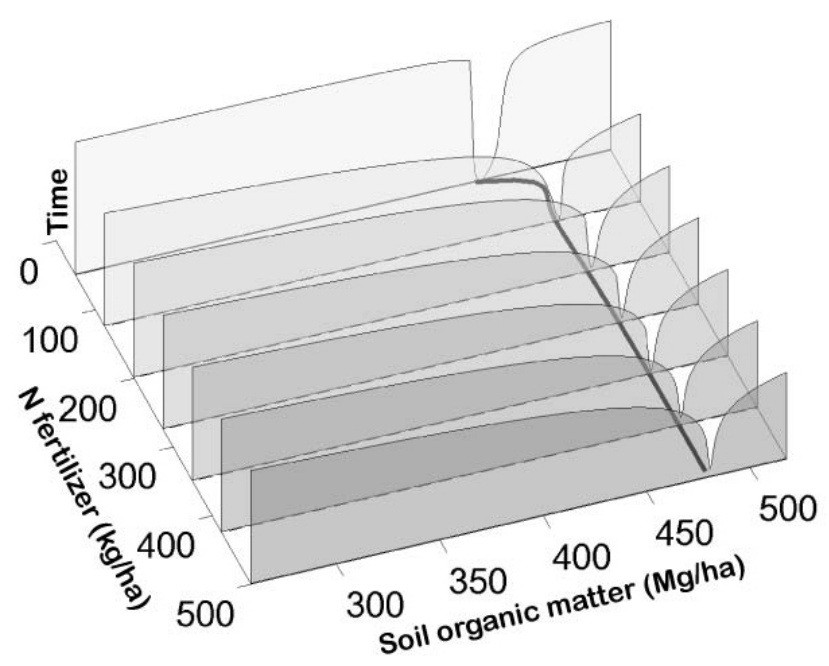

to external inputs and continuous high levels of grass production. The main goal of this strategy is fast response instead of resistance to change. The design on the fast response of external inputs has a contra-ecological consequence: the development of internal recycling, the growth phase, is halted.

Steering on output of the field and disregarding internal dynamics leads to frequent grassland renewals. With grassland renewal, the sod is destroyed, the soil is tilled, and the field is reseeded with high productive grass varieties. After renewal, the grassland starts accumulating organic matter again (Vellinga et al. 2004). However, after a few years the renewed grassland declines in production again. This decline is, however, only temporary, as the buildup of soil organic matter (the growth phase) is not matched with the mineralization capacity of soil biota (Hoogerkamp 1984), leading to a perceived deterioration of the grassland.

In combination with a sward deterioration caused by urine scorching, treading, winter mortality, and late mowing or grazing, frequent grassland renewal, including soil tillage, becomes an attractive option (Van Loo 1993). Grassland renewal keeps soil organic matter and its $\mathrm{N}$-supply at low levels. The development of the soil's internal recycling is associated with the increase of potential in the adaptive cycle. Rather than developing toward a quasi-equilibrium, the system is regularly disturbed, preventing it from developing the internal recycling. Within the adaptive cycle, the conventional strategy puts the agroecosystem in a short-cut loop from rapid growth phase to the reorganization phase $(\alpha$; Fig. 4).

The reorganization phase in the adaptive cycle with conventional farms is characterized by a low connectedness, high potential, and high resilience (see Fig. 4). The low connectedness causes the system to be leaky (Holling and Gunderson 2002). This results in large amounts of nitrogen being lost through leaching and gaseous emissions, causing environmental problems.

In ecosystems, the dynamics of the reorganization phase are characterized by physical structures and their residual vegetation (Holling 2001). The reorganization phase has a high uncertainty, meaning that the final outcome ( $\mathrm{K}$ phase) is uncertain. With the renewal of grasslands, external inputs of seeds and herbicide make sure that preferred species, namely high productive grass 
Fig. 4. Conventional farming short-circuits the adaptive cycle. The dynamics are characterized by fast feedbacks. Frequent disturbances prevent the system from developing recycling mechanisms in ecosystems associated with a high potential. The high inputs during the reorganization $(\alpha)$ phase enable a high potential and adaptability.

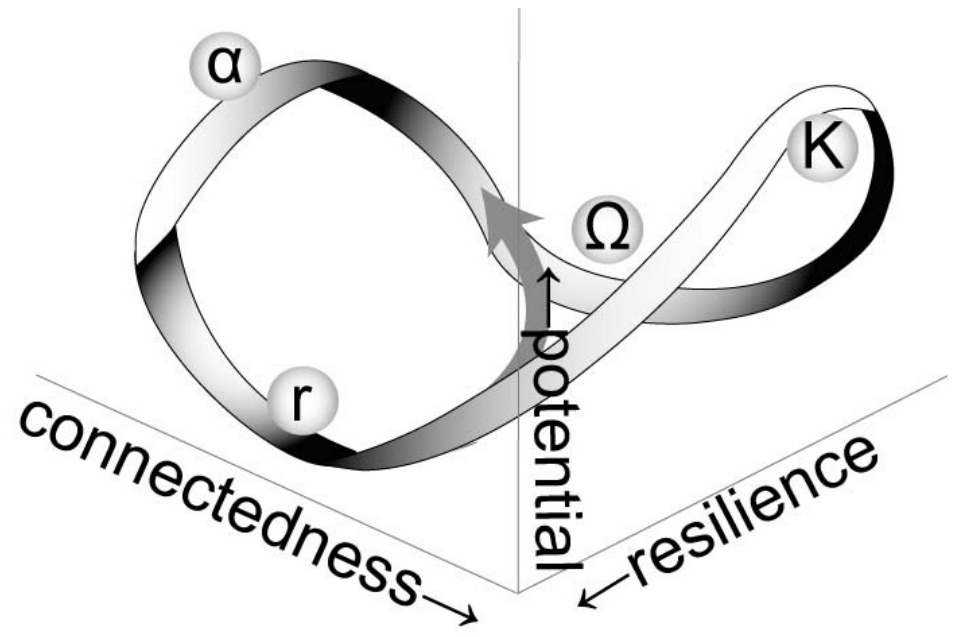

varieties, dominate during the reorganization phase. The large input of artificial fertilizer compensates for nutrient losses that normally occur in this phase, to offset a loss of potential.

\section{Panarchy}

Soil organic matter is a variable that connects multiscale ecological dynamics and farm management. For farms experimenting with the reinforcing measures, three main timescales influence the organic matter content of their soils. The longest is landscape evolution on a geological timescale of millennia, when glacial till and cover sands were deposited and land topography developed. Till deposits affect soil organic matter content through impeded soil drainage, which influences mineralization of organic matter. The next timescale comprises the centuries of reclamation. The top soil is created by human management. Remains of peat and heath were mixed or added to the soil to increase the agricultural value of the topsoil. Superimposed on the long-term processes is current management, such as plowing and manuring, affecting soil organic matter content on the scale of decades. The three timescales together create a heterogeneous soilscape (Veldkamp et al. 2001).
The aim of reaching high soil organic matter contents of fields can only be achieved by not disturbing the field with tillage and by accounting for the effects that the drivers of these timescales have. This requires a more ecological and long-term perspective on management actions.

High soil organic matter content at the field level is the cumulative result of historical management actions. As such, history is reflected in the smallscale landscape, which provides an identity (Antrop 2005) to the Northern Frisian Woodlands. In contrast, conventional grassland management calls for large scale homogenized fields, causing a loss of accumulated capital of soil organic matter and possibly regional identity.

Conventional management with its high reliance on artificial fertilizers and large machinery does not depend on locality and land use history. The frequent disturbance of plowing disconnects fields from their spatial position in the landscape and resets the accumulation of soil organic matter.

The access to artificial fertilizers and concentrates is essential for the conventional strategy. The high dependence on external resources and cheap energy inherently makes the strategy vulnerable for higher 
scale shocks such as energy scarcity (Anderies et al. 2007). Furthermore, the conventional strategy is closely tied to agricultural science and environmental regulations at regional, national, and European scale (van der Ploeg et al. 2007), which are based on assumptions of full control and steadystate conditions. This strategy, where inputs and outputs at farm level are well-monitored and easy to control, complies with the existing environmental policies that use static nutrient balances. Conventional management is thus much more controlled by its socio-technical regime than by its ecological context. In other words, the fields are much more connected to organizational levels of the farm and higher, rather than the landscape level.

Clearly both management strategies are embedded in forces that extend from the plot to the global scale. However, rather than alternative states, an alternative set of relationships within a multiscale setting applies to these systems. Conventional management seems to be much more part of institutional panarchy whereas the reinforcing measures are more ecologically embedded.

\section{Resilience}

Independent from fertilizer input, soil organic matter will increase. Thus, differences in soil organic matter content represent different positions on the trajectory of soil organic matter accumulation. During this trajectory, the response of the soil to disturbances changes gradually; the change from low soil organic matter to high soil organic matter content is long and strongly nonlinear. When a farmer intends to move from conventional management to the reinforcing management measures, the stocks of inorganic nitrogen and soil organic matter change over time (Fig. 5). First, a steep decline of mineral nitrogen in the soil occurs, because input of inorganic nitrogen is greatly reduced. After conversion, the nitrogen provided by soil organic matter will increase slowly (Whitehead 1995).

Near-equilibrium conditions associated with the reinforcing measures are resistant to frequently occurring disturbances. For example, biomass production on fields managed according to the reinforcing measures are less affected by variation in precipitation and temperature (Groot et al. 2007). The high soil organic matter content and welldeveloped rooting system of the fields provide a buffer to these changes. Moreover, changes in regulations or in price of external inputs will have less effect on the systems, because they use less of these external inputs.

In contrast, conventional grassland management with its frequent disturbances represents a system that is easily disrupted, for example, more highly affected by weather variation, but can also be easily adjusted because its controls (inputs) lie outside the field's borders. The lack of recycling creates a nearly linear system with a fast response. These properties make it more adaptable and easy to manage.

The transition toward more nutrient efficiency thus requires a trade-off: to decrease nitrogen losses and dependency on external finite and marketdependent resources, the system has to move from the reorganization and growth to the climax phase. The increase in internal regulation will make the system more efficient and resistant, but, according to the adaptive cycle, also less resilient.

\section{Adaptability}

As argued above, the accumulation of soil organic matter is slow and hardly affected by operational management. At field level, the adaptability of the reinforcing measures is thus low. This low fieldlevel adaptability however, can be compensated for at farm and regional level. The reinforcing measures combine well with other functions of the landscape (Wiskerke et al. 2003). For example, extra income is obtained by activities such as maintaining characteristic landscape elements of hedge rows, the conservation of meadow birds, or tourism. At the institutional level, the environmental cooperatives have been very successful in obtaining support from local, regional, and national institutes (Roep et al. 2003).

Conventional farming has a high adaptability at field level, by the high control the farmer can exert with application of external inputs such as artificial fertilizers, concentrates, seeds, and pesticides. The high adaptability is further enhanced by the dominant position of the conventional strategy within Dutch institutions, providing further support when shocks occur (van der Ploeg et al. 2007).

\section{Transformability}

The region as a whole has shown a high transformability in the socio-institutional domain 
Fig. 5. Modeled trajectory of change (line) in the phase space of mineral nitrogen $\left(\mathrm{N}_{\min }\right)$ and soil organic matter. Initial condition is a field after years of maize cultivation, based on Sonneveld et al. (2002), and afterward receiving $125 \mathrm{~kg}$ fertilizer N/ha. Mineral nitrogen determines the yield of the field and in 200 years the farmer will have almost the same yield with half of the external fertilizer input. The trajectory is strongly nonlinear, the fast variable of mineral nitrogen decreases steeply, and recovery of this variable is slow with the increase of soil organic matter.

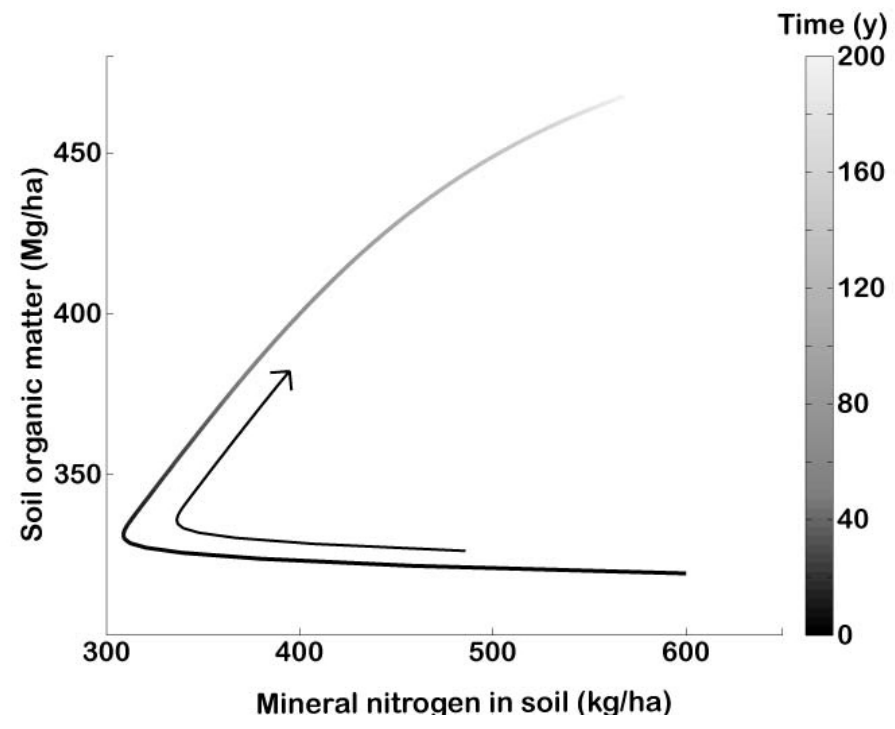

by creating the environmental cooperatives. From a governance perspective, a new system with new multilevel relationships was developed (Wiskerke et al. 2003). Transformations to other system configurations are not to be expected nor are they a goal, because current activities and social support are all based on maintaining a form of land-based agriculture connected to the landscape.

The prolonged success of the transformation is unsure because it depends on the slow variable of soil organic matter accumulation. Conventional farming practices of maize cultivation and grassland renewal are still widely practiced (Sonneveld et al. 2002). When plowed, the organic matter content will decrease drastically. Subsequently, the fields must be managed according to the needs of fields with low organic matter values that are responsive to fertilizer change.

The high adaptability and fast recovery of conventional farming are causing a trap of incremental adaptation (Anderies et al. 2006a). By incrementally adapting, short-term returns become a trade-off for other system configurations. Each small adaptation reinforces the dominant social and economic structures, further reinforcing the incremental adaptation process by economic forces and vested interests. The inertia thus generated by the land use history and biophysical processes might become so large that it precludes transformability of the system.

\section{Discussion of the resilience perspective}

Given the discussion above, we consider that the resilience perspective adds understanding to the system. In Table 1 we summarize the findings of the previous section.

A practical result of analyzing this case study with the resilience perspective is that it provides a possible explanation of the observed unrelated inputs and outputs of the farms in the region. The lack of correlation between inputs of nitrogen fertilizer and output of herbage appears to be a time lag. In Figure 6, we plotted the simulated input- 
Table 1. Summarized findings of our analysis of conventional managed systems and the reinforcing measures.

\begin{tabular}{lll}
\hline \hline Heuristic & Conventional management & Reinforcing measures \\
\hline Adaptive Cycle & from growth to reorganization & from growth to conservation \\
Panarchy & institutional panarchy & ecological panarchy \\
Resilience & fast return & resistant \\
Adaptability & high because of institutional connection & $\begin{array}{l}\text { low at field level/ high at farm level because of } \\
\text { multifunctional use }\end{array}$ \\
Transformability & low, incremental adaptation trap & \begin{tabular}{l} 
low, is still developing from past transformation \\
\hline
\end{tabular}
\end{tabular}

output relation of artificial fertilizer and consumable nitrogen at different time spans after plowing a maize field and converting it to grassland. The inputoutput relationship was calculated after simulating one year, five years, and 200 years over a range of $0-1200 \mathrm{~kg} / \mathrm{ha}$ of $\mathrm{N}$-fertilizer applications. The figure shows that the consumable $\mathrm{N}$ production $\left(\mathrm{kg} \mathrm{ha}^{-1}\right.$ $\left.\mathrm{yr}^{-1}\right)$ increases with time if not plowed, given a fixed fertilizer input $\left(\mathrm{kg} \mathrm{ha}^{-1} \mathrm{yr}^{-1}\right)$.

With increasing inputs, the relative contribution of soil $\mathrm{N}$ supply decreases. In other words, the dominance of internal dynamics decreases. This might explain why the difference in nutrient use efficiency was not observed earlier, because fertilizer applications of more than $400 \mathrm{~kg} / \mathrm{ha}$ were not uncommon, thus masking the difference. The area between the first year line and the equilibrium line is the modeled space of possible input-output relations. In Figure 6, we also plotted the observed (2006) input-output relations of farms in the region. First, this shows that regionally, the uncorrelated inputs and outputs are still visible after almost a decade of the nutrient management project. It furthermore demonstrates that most actual data points are within the modeled space of input-output relations. It also illustrates the limitations of the model approach. The almost vertical increase of nitrogen in consumable biomass in equilibrium systems is not observed in practice. In the model, all sources of external nitrogen are considered to be fertilizer, whereas fields also receive external nitrogen via nitrogen deposition and nitrogen fixation by leguminous plants (up to $70\left[\mathrm{~kg} \mathrm{ha}^{-1}\right.$ $\left.\mathrm{yr}^{-1}\right]$ ) in comparable farming systems (Sonneveld et al. 2008). This input, together with the nitrogen supplied by mineralization of soil organic matter, is then labeled as soil nutrient supply, shifting the Yaxis and observed fertilizer applications to the right. Furthermore, we assumed that the whole farm was managed as one field with a consistent strategy, whereas different strategies evolved (Groot et al. 2006) and not all fields were managed similarly. The location of points below the first year line can be explained by the fact that these are farm-scale figures, and not all fields are grasslands for some farms. A field used for maize cultivation, for example, receives manure that would otherwise have been applied to grassland. The grasslands of these farms in turn receive more fertilizer.

Importantly, Figure 6 shows that input-output relations are time-dependent. The recognition that grasslands are not in equilibrium and are internally developing toward a system with other characteristics needs to be taken into account in further research. In Figure 6, time and space relations are combined. This hides the possibility that nutrient efficient systems are developed on favorable locations. Three qualitatively different temporal processes of the panarchy, i.e., landscape evolution, reclamation history, and current land management, together created a heterogeneous landscape with a potentially high soil organic matter content and associated high nutrient use efficiency. The theoretical trajectory of change (Fig. 5) has probably never been followed completely. The panarchy that created the heterogeneity of resources 
Fig. 6. The change of input-output relation of the consumable part of the plant to external nitrogen input. For a field after years of maize cultivation, the dotted line is the response of the consumable part to fertilizer after 1 year, the dashed line after 5 years, and the solid line when the system has reached equilibrium. The circles are the input-output relation of farms in 2006.

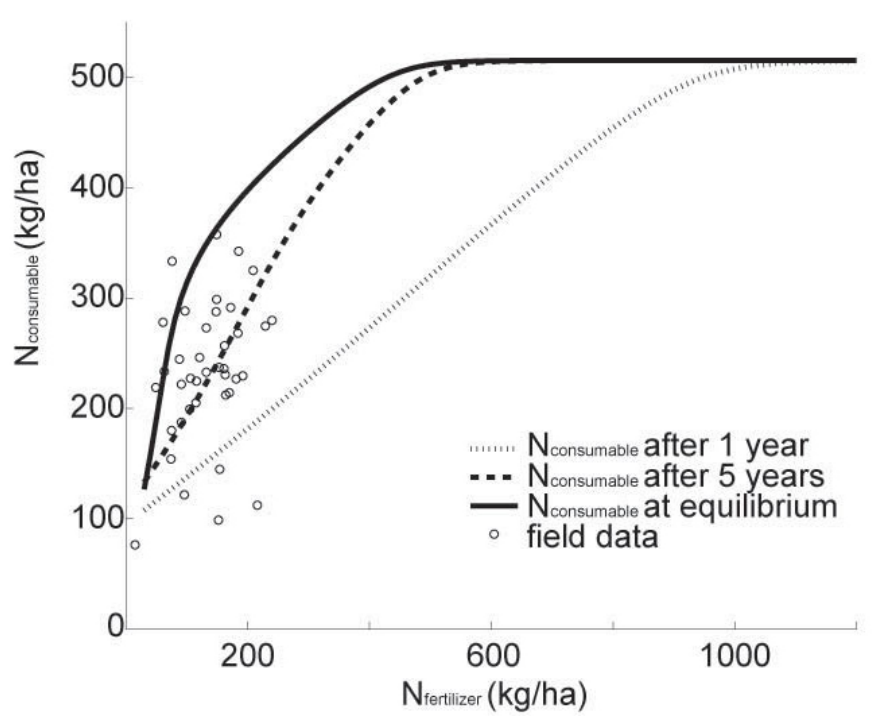

in the landscape provides local landscapeembedded opportunities for high $\mathrm{N}$-efficiencies.

\section{RETHINKING RESILIENCE OF AGROECOSYSTEMS}

Although we used a temporal model at field-farm level, and only skimmed over spatial and social dynamics, several elements of this study are relevant for further resilience-based studies of human dominated agroecosystems. For modern, conventionally managed agricultural systems, the heuristic of the adaptive cycle is less applicable. These systems do not follow the adaptive cycle but rather a short circuit version: from reorganization to exploitation to reorganization (Fig. 4). High output is reached at the cost of high losses, as in short circuits. In Holling and Gunderson (2002), this trajectory is hinted at for both arid grassland systems and more productive systems. Systems in this trajectory are continuously adapting to external variability and, according to Holling and Gunderson (2002), they are remarkably resilient. Although globally modern agroecosystems are seen as the epitome of nonresilience with their monocultures and energy-intensive farming practices (Holling and Meffe 1996), they are highly resilient at farm-field level. The short-term focus and institutional setting of modern agroecosystems leads to properties of high resilience and high potential that cannot be observed in natural ecosystems.

The continuous disturbance by farm management prevents the system from developing a structure of internal recycling. The high inputs during the reorganization phase enable a high capacity and adaptability of the agroecosystem. The high adaptability of the intensively managed systems has resulted in a system that is unlikely to transform fundamentally. Most disturbances can be dealt with within the existing system configuration. Societies might desire agricultural transformations (Veldkamp et al.2009), but are hindered by the high adaptability and resilience of conventional strategies. This trap of incremental adaptation (Anderies et al. 2006a) might be common in intensively managed agroecosystems as found by others (Allison and Hobbs 2004, Anderies et al. 2006a). The trap is deepened by destroying its transformability and 
long-term accumulated ecological capital, in our case soil organic matter, leading to an increasing dependency on external inputs.

\section{Panarchy and governance}

The development of environmental cooperatives in the Northern Frisian Woodlands resulted in an increase of socioeconomic capital. Self-governance and the interest in developing a multifunctional agroecosystem are illustrative of this capital. The increase of soil organic matter as a result of the reinforcing measures contributes to the development of ecological capital. Therefore, from a sustainability perspective, the region has developed to a more sustainable landscape scale system that is less resilient at the field level. The success of the environmental cooperatives to establish a new type of regional governance however, is dependent on the intrinsically slow dynamics at field level of soil organic matter accumulation. Institutional dynamics require fast and measurable results, which do not match with the slow ecological dynamics at field level. This cross-scale dynamic system property is often difficult to address in our governance approaches (Cash et al. 2006). The concept of panarchy might prove insightful for tackling this kind of interaction at different time-scales.

\section{CONCLUSIONS}

A dynamic farm model was used to evaluate the long-term effects of the reinforcing measures in the Northern Frisian Woodlands. Simulations show that no alternative stable state exists for soil organic matter, considered to be a key indicator of sustainability, within a plausible range of fertilizer applications. The slow variable of soil organic matter accumulation is hardly affected by operational management. The observed differences in soil organic matter content and nutrient use efficiency probably represent a time lag of longterm nonequilibrium system development. Rather than alternative stable states, observed differences in N-efficiency represent a time lag effect. Stopping grassland renewal will allow ecological processes to mature and the slow buildup of soil organic matter capital. The panarchy created heterogeneity of resources in the landscape providing local landscape embedded opportunities for high $\mathrm{N}$-efficiencies. Panarchy proved to be especially insightful for studying long-term developments, which are generally overlooked by traditional agronomic studies.

In contrast, modern conventional dairy farms with short-term focus and their institutional setting leads to properties of high resilience and high potential that cannot be observed in natural ecosystems. These systems shortcut the adaptive cycle by frequent grassland renewals, resulting in high resilience and adaptability. This comes at the cost of long-term accumulated ecological capital of soil organic matter and transformability, thus reinforcing the incremental adaptation trap. The continuous disturbance by farm management prevents the system from developing structures of internal recycling. These systems however, tend to be locked up in the incremental adaptation trap, hindering society's desire for agricultural transformations. Analysis of such a human dominated agroecosystem reveals that rather than alternative states, an alternative set of relationships within a multiscale setting applies, indicating the importance for embedding panarchy in the analysis of sustainable development goals in agroecosystems.

Responses to this article can be read online at:

http://www.ecologyandsociety.org/voll6/iss1/art39/ responses/

\section{Acknowledgments:}

We thank Sjaak Conijn and Jeroen Groot for commenting on the model and providing data on grassland dynamics and the Northern Frisian Woodlands. We also wish to thank Ken Giller and anonymous reviewers for their constructive and extensive review of an earlier version of this paper. We appreciate the facilitation and financial support provided by TransForum.

\section{LITERATURE CITED}

Allison, H. E., and R. J. Hobbs. 2004. Resilience, adaptive capacity, and the "lock-in trap" of the Western Australian agricultural region. Ecology and Society 9(1): 3. [online] URL: http://www.ecol ogyandsociety.org/vol9/iss1/art3/. 
Anderies, J. M., A. A. Rodriguez, M. A. Janssen, and O. Cifdaloz. 2007. Panaceas, uncertainty, and the robust control framework in sustainability science. Proceedings of the National Academy of Sciences of the United States of America 104 (39):15194-15199.

Anderies, J. M., P. Ryan, and B. H. Walker. $2006 a$. Loss of resilience, crisis, and institutional change: lessons from an intensive agricultural system in southeastern Australia. Ecosystems 9(6):865-878.

Anderies, J. M., B. H. Walker, and A. P. Kinzig. $2006 b$. Fifteen weddings and a funeral: case studies and resilience-based management. Ecology and Society 11(1): 21. [online] URL: http://www.ecolog yandsociety.org/vol11/iss1/art21/.

Antrop, M. 2005. Why landscapes of the past are important for the future. Landscape and Urban Planning 70(1-2):21-34.

Bennett, E. M., G. S. Cumming, and G. D. Peterson. 2005. A systems model approach to determining resilience surrogates for case studies. Ecosystems 8 (8):945-957.

Bouma, J., J. A. de Vos, M. P. W. Sonneveld, G. B. M. Heuvelink, and J. J. Stoorvogel. 2008. The role of scientists in multiscale land use analysis: lessons learned from Dutch communities of practice. Advances in Agronomy 97:175-237.

Brand, F. S., and K. Jax. 2007. Focusing the meaning(s) of resilience: resilience as a descriptive concept and a boundary object. Ecology and Society 12(1): 23. [online] URL: http://www.ecologyandso ciety.org/vol12/iss1/art23/.

Carpenter, S. R., H. A. Mooney, J. Agard, D. Capistrano, R. S. Defries, S. Diaz, T. Dietz, A. K. Duraiappah, A. Oteng-Yeboah, H. M. Pereira, C. Perrings, W. V. Reid, J. Sarukhan, R. J. Scholes, and A. Whyte. 2009. Science for managing ecosystem services: beyond the Millennium Ecosystem Assessment. Proceedings of the National Academy of Sciences of the United States of America 106(5):1305-1312.

Carpenter, S. R., B. Walker, J. M. Anderies, and N. Abel. 2001. From metaphor to measurement: resilience of what to what? Ecosystems 4 (8):765-781.
Cash, D. W., W. Adger, F. Berkes, P. Garden, L. Lebel, P. Olsson, L. Pritchard, and O. Young. 2006. Scale and cross-scale dynamics: governance and information in a multilevel world. Ecology and Society 11(2): 8. [online] URL: http://www.ecology andsociety.org/vol11/iss2/art8/.

Eshuis, J., and M. Stuiver. 2005. Learning in context through conflict and alignment: farmers and scientists in search of sustainable agriculture. Agriculture and Human Values 22(2):137-148.

Foley, J. A., R. DeFries, G. P. Asner, C. Barford, G. Bonan, S. R. Carpenter, F. S. Chapin, M. T. Coe, G. C. Daily, H. K. Gibbs, J. H. Helkowski, T. Holloway, E. A. Howard, C. J. Kucharik, C. Monfreda, J. A. Patz, I. C. Prentice, N. Ramankutty, and P. K. Snyder. 2005. Global consequences of land use. Science 309(5734):570-574.

Folke, C. 2006. Resilience: the emergence of a perspective for social-ecological systems analyses. Global Environmental Change 16(3):253-267.

Giller, K. E., E. C. Rowe, N. de Ridder, and H. van Keulen. 2006. Resource use dynamics and interactions in the tropics: scaling up in space and time. Agricultural Systems 88(1):8-27.

Gomiero, T., M. Giampietro, and K. Mayumi. 2006. Facing complexity on agro-ecosystems: a new approach to farming system analysis. International Journal of Agricultural Resources, Governance and Ecology 5(2-3):116-144.

Gordon, L. J., G. D. Peterson, and E. M. Bennett. 2008. Agricultural modifications of hydrological flows create ecological surprises. Trends in Ecology and Evolution 23(4):211-219.

Groot, J. C. J., W. A. H. Rossing, and E. A. Lantinga. 2006. Evolution of farm management, nitrogen efficiency and economic performance on Dutch dairy farms reducing external inputs. Livestock Science 100(2-3):99-110.

Groot, J. C. J., W. A. H. Rossing, E. A. Lantinga, and $H$. van Keulen. 2003. Exploring the potential for improved internal nutrient cycling in dairy farming systems, using an eco-mathematical model. NJAS - Wageningen Journal of Life Sciences 51 (1-2):165-194. 
Groot, J. C. J., J. D. van der Ploeg, F. P. M. Verhoeven, and E. A. Lantinga. 2007. Interpretation of results from on-farm experiments: manurenitrogen recovery on grassland as affected by manure quality and application technique. 1. An agronomic analysis. NJAS - Wageningen Journal of Life Sciences 54(3):235-254.

Hanegraaf, M. C., E. Hoffland, P. J. Kuikman, and L. Brussaard. 2009. Trends in soil organic matter contents in Dutch grasslands and maize fields on sandy soils. European Journal of Soil Science 60 (2):213-222.

Hassink, J. 1994. Effects of soil texture and grassland management on soil organic $\mathrm{C}$ and $\mathrm{N}$ and rates of $\mathrm{C}$ and $\mathrm{N}$ mineralization. Soil Biology and Biochemistry 26(9):1221-1231.

Holling, C. S. 2001. Understanding the complexity of economic, ecological, and social systems. Ecosystems 4(5):390-405.

Holling, C. S., and L. H. Gunderson. 2002. Resilience and adaptive cycles. Pages 25-62 in L. H. Gunderson and C. S. Holling, editors. Panarchy: understanding transformations in systems of humans and nature. Island Press, Washington, D. C., USA.

Holling, C. S., and G. K. Meffe. 1996. Command and control and the pathology of natural resource management. Conservation Biology 10(2):328-337.

Hoogerkamp, M. 1984. Changes in productivity of grassland with ageing. Dissertation. Landbouwhogeschool Wageningen, Wageningen, The Netherlands.

Janssen, B. H. 1996. Nitrogen mineralization in relation to $\mathrm{C}: \mathrm{N}$ ratio and decomposability of organic materials. Plant and Soil 181(1):39-45.

Janzen, H. H. 2005. Soil carbon: a measure of ecosystem response in a changing world? Canadian Journal of Soil Science 85(4):467-480.

Kiers, E. T., R. R. B. Leakey, A. M. Izac, J. A. Heinemann, E. Rosenthal, D. Nathan, and J. Jiggins. 2008. Ecology: agriculture at a crossroads. Science 320(5874):320-321.

Kinzig, A. P., P. Ryan, M. Etienne, H. Allison, T. Elmqvist, and B. H. Walker. 2006. Resilience and regime shifts: assessing cascading effects. Ecology and Society 11(1): 20. [online] URL: http://www.e cologyandsociety.org/vol11/iss1/art20/.

Kohn, R. A., Z. Dou, J. D. Ferguson, and R. C. Boston. 1997. A sensitivity analysis of nitrogen losses from dairy farms. Journal of Environmental Management 50(4):417-428.

Kremen, C., and R. S. Ostfeld. 2005. A call to ecologists: measuring, analyzing, and managing ecosystem services. Frontiers in Ecology and the Environment 3(10):540-548.

Milestad, R., and I. Darnhofer. 2003. Building farm resilience: the prospects and challenges of organic farming. Journal of Sustainable Agriculture 22 (3):81-97.

Reeves, D. W. 1997. The role of soil organic matter in maintaining soil quality in continuous cropping systems. Soil and Tillage Research 43(1-2):131-167.

Reijs, J. W., M. P. W. Sonneveld, P. Sørensen, R. L. M. Schils, J. C. J. Groot, and E. A. Lantinga. 2007. Effects of different diets on utilization of nitrogen from cattle slurry applied to grassland on a sandy soil in The Netherlands. Agriculture, Ecosystems and Environment 118(1-4):65-79.

Reijs, J. W., F. P. M. Verhoeven, J. van Bruchem, J. D. van der Ploeg, and E. A. Lantinga. 2004. The nutrient management project of the VEL and VANLA environmental co-operatives. Pages 149-181 in J. S. C. Wiskerke and J. D. van der Ploeg, editors. Seeds of transition. Royal Van Gorcum, Assen, The Netherlands.

Renting, H., and J. D. van der Ploeg. 2001. Reconnecting nature, farming and society: environmental cooperatives in the Netherlands as institutional arrangements for creating coherence. Journal of Environmental Policy and Planning 3 (2):85-101.

Roep, D., J. D. van der Ploeg, and J. S. C. Wiskerke. 2003. Managing technical-institutional design processes: some strategic lessons from environmental co-operatives in the Netherlands. NJAS Wageningen Journal of Life Sciences 51 (1-2):195-217.

Scheffer, M., S. Carpenter, J. A. Foley, C. Folke, and B. Walker. 2001. Catastrophic shifts in ecosystems. Nature 413(6856):591-596. 
Scheffer, M., and S. R. Carpenter. 2003. Catastrophic regime shifts in ecosystems: linking theory to observation. Trends in Ecology \& Evolution 18(12):648-656.

Schröder, J. J., H. F. M. Aarts, H. F. M. ten Berge, H. van Keulen, and J. J. Neeteson. 2003. An evaluation of whole-farm nitrogen balances and related indices for efficient nitrogen use. European Journal of Agronomy 20(1-2):33-44.

Schulp, C. J. E., and A. Veldkamp. 2008. Long-term landscape - land use interactions as explaining factor for soil organic matter variability in Dutch agricultural landscapes. Geoderma 146(3-4):457-465.

Sonneveld, M. P. W., J. Bouma, and A. Veldkamp. 2002. Refining soil survey information for a Dutch soil series using land use history. Soil Use and Management 18(3):157-163.

Sonneveld, M. P. W., J. J. Schröder, J. A. de Vos, G. J. Monteny, J. Mosquera, J. M. G. Hol, E. A. Lantinga, F. P. M. Verhoeven, and J. Bouma. 2008. A whole-farm strategy to reduce environmental impacts of nitrogen. Journal of Environmental Quality 37(1):186-195.

Stuiver, M., J. D. van der Ploeg, and C. Leeuwis. 2003. The VEL and VANLA environmental cooperatives as field laboratories. NJAS - Wageningen Journal of Life Sciences 51(1-2):27-39.

Van den Pol-van Dasselaar, A., and E. A. Lantinga. 1995. Modeling the carbon-cycle of grassland in the Netherlands under various management strategies and environmental-conditions. Netherlands Journal of Agricultural Science 43(2):183-194.

van der Ploeg, J. D. 2003. The virtual farmer: past, present, and future of the Dutch peasantry. Royal Van Gorcum, Assen, The Netherlands.

van der Ploeg, J. D., J. C. J. Groot, F. P. M. Verhoeven, and E. A. Lantinga. 2007. Interpretation of results from on-farm experiments: manurenitrogen recovery on grassland as affected by manure quality and application technique. 2. A sociological analysis. NJAS - Wageningen Journal of Life Sciences 54(3):255-268.

Van Loo, E. N. 1993. On the relation between tillering, leaf area dynamics and growth of perennial ryegrass (Lolium perennne L.).
Dissertation. Wageningen University, Wageningen, The Netherlands.

Veldkamp, A., K. Kok, G. H. J. De Koning, J. M. Schoorl, M. P. W. Sonneveld, and P. H. Verburg. 2001. Multi-scale system approaches in agronomic research at the landscape level. Soil and Tillage Research 58(3-4):129-140.

Veldkamp, A., A. C. Van Altvorst, R. Eweg, E. Jacobsen, A. Van Kleef, H. Van Latesteijn, S. Mager, H. Mommaas, P. J. A. M. Smeets, L. Spaans, and J. C. M. Van Trijp. 2009. Triggering transitions towards sustainable development of the Dutch agricultural sector: TransForum's approach. Agronomy for Sustainable Development 29:87-96.

Vellinga, T. V., A. Van den Pol-van Dasselaar, and P. J. Kuikman. 2004. The impact of grassland ploughing on $\mathrm{CO} 2$ and $\mathrm{N} 2 \mathrm{O}$ emissions in the Netherlands. Nutrient Cycling in Agroecosystems 70:33-45.

Walker, B., L. Gunderson, A. Kinzig, C. Folke, S. Carpenter, and L. Schultz. 2006. A handful of heuristics and some propositions for understanding resilience in social-ecological systems. Ecology and Society 11(1): 13. [online] URL: http://www.ecolog yandsociety.org/vol11/iss1/art13/.

Walker, B., and J. A. Meyers. 2004. Thresholds in ecological and social-ecological systems: a developing database. Ecology and Society 9(2): 3. [online] URL: http://www.ecologyandsociety.org/vol9/ iss2/art3.

Whitehead, D. C. 1995. Grassland nitrogen. CABI, Wallingford, UK.

Whitehead, D. C., A. W. Bristow, and D. R. Lockyer. 1990. Organic matter and nitrogen in the unharvested fractions of grass swards in relation to the potential for nitrate leaching after ploughing. Plant and Soil 123(1):39-49.

Whitmore, A. P., N. J. Bradbury, and P. A. Johnson. 1992. Potential contribution of ploughed grassland to nitrate leaching. Agriculture, Ecosystems \& Environment 39(3-4):221-233.

Wiskerke, J. S. C., B. B. Bock, M. Stuiver, and H. Renting. 2003. Environmental co-operatives as a new mode of rural governance. NJAS - Wageningen Journal of Life Sciences 51(1-2):9-25. 
Appendix 1. Dynamic simulation of nitrogen and carbon stocks in a grassland-based dairy farming system.

\section{Model formulation}

For full model description see Groot et al. (2003) and Reijs et al. (2007)

\section{Plantgrowth}

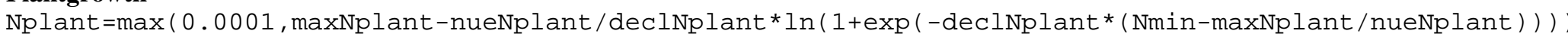
rangeNcons $=$ maxNcons $+\mathrm{NconsB}$;

Ncons $=\max (0.00001$, rangeNcons-nueNcons/declNcons*ln $(1+\exp (-\operatorname{declNcons}$ (Nmin-rangeNcons/nueNcons $)))-\mathrm{NconsB})$

DMplant $=\max (0.001$, maxDMplant-nueDMplant/declDMplant*ln (1+exp (-declDMplant* (Nplant-maxDMplant/nueDMplant) ) )

DMcons $=\max (0.01, \operatorname{maxDMcons}-$ nueDMcons $/$ declDMcons $\ln (1+\exp (-\operatorname{declDMcons}$ (Ncons-maxDMcons/nueDMcons $)))$

DMubm $=$ DMplant - DMcons

Nubm=Nplant-Ncons

Ccons $=$ DMcons ${ }^{*} \mathrm{CC}$

Cubm $=\mathrm{DMubm}{ }^{*} \mathrm{CC}$

Cplant $=$ DMplant ${ }^{*} \mathrm{CC}$

\section{Animal conversion}

MilkEff $=-M i l k A * N c o n s / D M c o n s+M i l k B$

phiUr $=U r A * N c o n s / D M c o n s+U r B$

phiF=1-phiUr

exretedN=Ncons $-\mathrm{Ncons}$ MilkEff;

\section{Mineralisation}

$\mathrm{qF}=($ volatilF*exretedN*phiF $) /($ Ccons* $(1-\mathrm{dH}))$

qubm $=$ Nubm / (Cubm)

MUr=volatilUr*exretedN*phiUr

$\mathrm{MF}=\mathrm{kF} /(1-\mathrm{smEff}){ }^{*} \mathrm{Ccons} *(1-\mathrm{dH}) *\left(\mathrm{qF}-\mathrm{smEff}{ }^{*} \mathrm{qsm}\right)$

Mubm=kubm/ (1-smEff) ${ }^{*} \mathrm{Cubm} *($ qubm-smEff* $q \mathrm{sm})$

Msom $=k$ som $/(1-$ smEff $){ }^{*} \mathrm{Csom} *($ Nsom/Csom-smEff* $\mathrm{qsm})$

\section{State variables}

Nmin ' $=$ inp $-W^{*} \mathrm{Nmin}+\mathrm{MUr}+\mathrm{MF}+\mathrm{Mubm}+\mathrm{Ms}$ om

$\mathrm{Csom}^{\prime}=(1-\mathrm{kF}){ }^{*} \mathrm{Ccons}{ }^{*}(1-\mathrm{dH})+(1-\mathrm{kubm}){ }^{*} \mathrm{Cubm}-\mathrm{ksom}{ }^{*} \mathrm{Csom}$

$\mathrm{Nsom}^{\prime}=\left(\right.$ Ncons$\left.{ }^{\star} \mathrm{phiF}\right)-\mathrm{MF}+\mathrm{Nubm}-\mathrm{Mubm}-\mathrm{Msom}$ 


\begin{tabular}{|c|c|c|}
\hline \multicolumn{3}{|l|}{ Abbreviations: } \\
\hline \multicolumn{3}{|l|}{$\mathrm{N}=$ nitrogen } \\
\hline \multicolumn{3}{|l|}{$\mathrm{C}=$ carbon } \\
\hline \multicolumn{3}{|l|}{$\max =\operatorname{maximum}$} \\
\hline \multicolumn{3}{|c|}{ nue=Nitrogen use Efficiency } \\
\hline \multicolumn{3}{|c|}{$\begin{array}{l}\text { decl=decline of nitrogen use Efficiency } \\
\text { cons=consumed }\end{array}$} \\
\hline \multicolumn{3}{|c|}{$\mathrm{DM}=$ Dry Matter } \\
\hline \multicolumn{3}{|c|}{ Ubm=unharvested biomass } \\
\hline \multicolumn{3}{|c|}{ Eff=efficiency } \\
\hline \multicolumn{3}{|c|}{$A=$ gradient } \\
\hline \multicolumn{3}{|l|}{$B=i n t e r c e p t$} \\
\hline \multicolumn{3}{|c|}{$\begin{array}{l}\text { phi=fraction that ends up in substance } \\
\text { Ur=urine }\end{array}$} \\
\hline \multicolumn{3}{|l|}{$\mathrm{F}=\mathrm{faeces}$} \\
\hline \multicolumn{3}{|c|}{$\mathrm{q}=\mathrm{N} / \mathrm{C}$ fraction } \\
\hline \multicolumn{3}{|c|}{$\mathrm{k}=$ mineralisation rate } \\
\hline \multicolumn{3}{|c|}{ M=mineralisation } \\
\hline \multicolumn{3}{|c|}{$\mathrm{sm}=$ soilmicrobes } \\
\hline \multicolumn{3}{|c|}{ som=soil organic matter } \\
\hline \multicolumn{3}{|c|}{ dH=digestibility consumed biomass } \\
\hline \multicolumn{3}{|c|}{$\mathrm{W}=$ fractional rate of Nmin withdrawal } \\
\hline parameter & value & Unit \\
\hline declDMcons & 0.0351 & $\mathrm{~kg}^{-1}$ \\
\hline declDMplant & 0.00900 & $\mathrm{~kg}^{-1}$ \\
\hline declNcons & 0.0242 & $\mathrm{~kg}^{-1}$ \\
\hline declNplant & 0.0160 & $\mathrm{~kg}^{-1}$ \\
\hline maxDMcons & 12900 & $\mathrm{~kg} \mathrm{ha}^{-1}$ year $^{-1}$ \\
\hline maxDMplant & 26000 & $\mathrm{~kg} \mathrm{ha}^{-1}$ year $^{-1}$ \\
\hline maxNcons & 515 & $\mathrm{~kg} \mathrm{ha}^{-1}$ year $^{-1}$ \\
\hline maxNplant & 667 & $\mathrm{~kg} \mathrm{ha}^{-1}$ year $^{-1}$ \\
\hline NconsB & 50 & $\mathrm{~kg} \mathrm{ha}^{-1}$ year $^{-1}$ \\
\hline nueDMcons & 42.3 & $\mathrm{~kg} \mathrm{~kg}^{-1} \mathrm{ha}^{-1}$ year $^{-1}$ \\
\hline nueDMplant & 76.1 & $\mathrm{~kg} \mathrm{~kg}^{-1} \mathrm{ha}^{-1}$ year $^{-1}$ \\
\hline nueNcons & 0.615 & $\mathrm{~kg} \mathrm{~kg}^{-1} \mathrm{ha}^{-1}$ year $^{-1}$ \\
\hline nueNplant & & $\mathrm{kg} \mathrm{kg}^{-1} \mathrm{ha}^{-1}$ year $^{-1}$ \\
\hline $\mathrm{CC}$ & 0.405 & $\mathrm{~kg} \mathrm{~kg}^{-1}$ \\
\hline $\mathrm{dH}$ & 0.65 & $\mathrm{~kg} \mathrm{~kg}^{-1}$ \\
\hline kubm & 0.4 & year ${ }^{-1}$ \\
\hline qsm & 0.125 & - \\
\hline smEff & 0.3 & $\mathrm{~kg} \mathrm{~kg}^{-1}$ \\
\hline $\mathrm{W}$ & 0.95 & year ${ }^{-1}$ \\
\hline ksom & 0.015 & year $^{-1}$ \\
\hline Csom & 1851336 & $\mathrm{~kg} \mathrm{ha}^{-1}$ year $^{-1}$ \\
\hline Nmin & 500 & $\mathrm{~kg} \mathrm{ha}^{-1}$ year $^{-1}$ \\
\hline Nsom & 13503 & $\mathrm{~kg} \mathrm{ha}^{-1}$ year $^{-1}$ \\
\hline $\mathrm{kF}$ & 0.4 & year $^{-1}$ \\
\hline MilkA & 7 & $\mathrm{~kg} \mathrm{~kg}^{-1}$ \\
\hline MilkB & 0.45 & $\mathrm{~kg} \mathrm{~kg}^{-1}$ \\
\hline UrA & 13.8 & $\mathrm{~kg} \mathrm{~kg}^{-1}$ \\
\hline $\mathrm{UrB}$ & 0.247 & $\mathrm{~kg} \mathrm{~kg}^{-1}$ \\
\hline volatilf & 0.97 & - \\
\hline volatilur & 0.45 & - \\
\hline
\end{tabular}

Ecology and Society 16(1): 39 http://www.ecologyandsociety.org/vol16/iss1/art39/

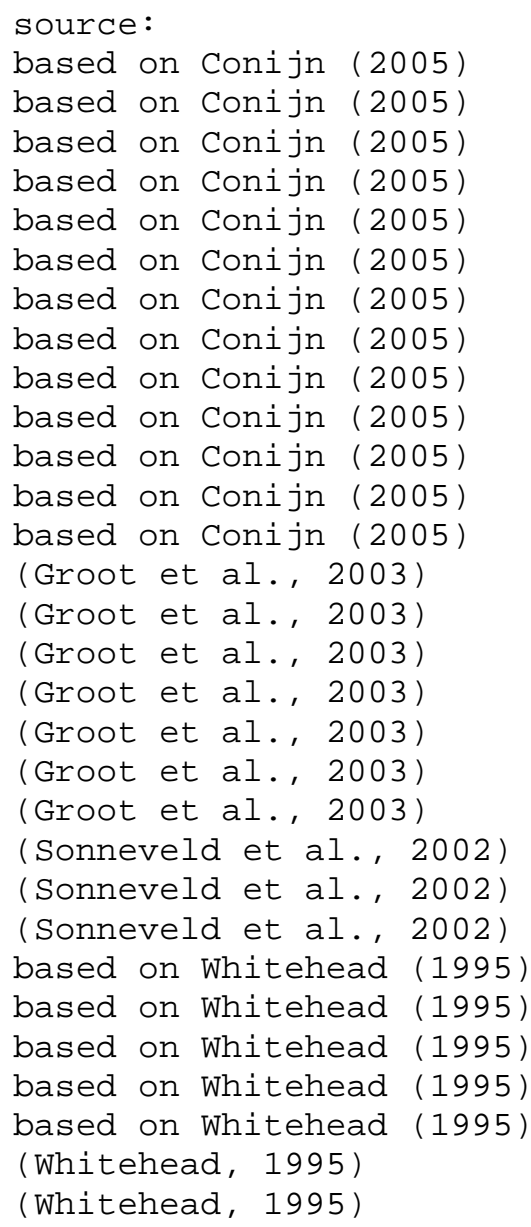

